\title{
COMPARATIVE STUDY OF IN VITRO ANTIMICROBIAL ACTIVITIES OF FOENICULUM VULGARE MILL. (UMBELLIFERAE) EXTRACT
}

\author{
Khadija Dahak and Moha Taourirte \\ Laboratory of Bio-organic Chemistry and Macromolecular (LCBM), Department of Chemical Sciences, \\ Faculty of Science and Technology Gueliz (FSTG), Cadi Ayyad University 40000, MarrakeCh, Morocco
}

Received 2013-09-19, Revised 2013-09-25; Accepted 2013-10-12

\begin{abstract}
The importance to push scientifically the investigations on the organic extracts of the plants aromatic as potential source of new antimicrobial compounds comes from the traditional use of the plants. However, the consumption of these natural products requires à thorough research in this field. The antimicrobial effect of organic and aqueous leaves extracts of Foeniculum vulgare Mill., However, which makes difficult this antimicrobial activity, is the insolubility of organic extracts in water. The standard M27-T technique is basically used to cure this problem. The microorganisms under examination were Staphylococcus aureus, Pseudomonas aeruginosa, Enterococcus hirea, Escherichia coli and Candida albicans. The M27-T technique allowed us to determine the Minimum Inhibitory Concentrations (MICs) of different extracts. Therefore, the test's results showed that the all samples were clearly different in terms of antimicrobial activities. All extracts of Foeniculum vulgare showed the most activity on all the microorganisms tested. The most significant and active extract under study were methanol and ethyl acetate on all the bacteria tested in comparaison to the hexane and aqueous extracts. On the other hand, the results of antimicrobial activity of aqueous extract were more compelling than the hexane and dichloromethane extracts when used on Candida albicans (ATCC and CBS) (MIC $=0,78 \mathrm{mg} \mathrm{mL}^{-1}$ ). It then appear that $C$. albicans ATCC is the least susceptible microorganisms to the ethyl acetate extract. The chloramphenicol, amoxicillin and amphotericin B were used as standard antibiotics to carry this study.
\end{abstract}

\section{Keywords: Leaves Extracts, Foeniculum Vulgare, Antimicrobial Activity}

\section{INTRODUCTION}

Foeniculum vulgare Mill., which is commonly known as fennel, belongs to the Apiaceae (Umbelliferae) family. It is an annual, biennial or perennial herbs and typical aromatic plant that grows in several regions all over the world. It is growing to a height ranging from 70 to $200 \mathrm{~cm}$. it grows wild in most regions, especially the west and south regions of turkey.

Fennel, which is largely planted in temperate and tropical regions of the world, is extensively used for medicine purposes and as a culinary spice (Tanira et al., 1996; Beaux et al., 1997; Patra et al., 2002; Barros et al., 2010).

They are also known for a wide range of activities , like diuretic, anti-inflammatory, analgesic, antipyretic, antispasmodic, antidiabetic and antioxidant actions (Beaux et al., 1997; El Bardai et al., 2001; Oktay et al., 2003; Choi and Hwang, 2004; Heinrich, 2005; Conforti et al., 2006; Abed, 2007; Surveswaran et al., 2007; Marino et al., 2007). Fennel's leaves and mature fruits are basically used as flavoring agents in food

\section{Corresponding Author: Khadija Dahak, Laboratory of Bio-organic Chemistry and Macromolecular (LCBM), Department of Chemical Sciences, Faculty of Science and Technology Gueliz (FSTG), Cadi Ayyad University 40000, MarrakeCh, Morocco}


product such as liqueurs, pickles, bread, pastries and cheese. They are also used in cosmetic and pharmaceutics (Telci et al., 2009).

The essential oil, one of the wide uses of fennel, was the most frequently investigated, in which antioxidant, antimicrobial, antidiabetic and hepatoprotective were actively showed (Ruberto et al., 2000; Ozbek et al., 2003; Faudale et al., 2008; El-Soud et al., 2011). They entail several monoterpenes and phenylpropanoids, where trans-anethole, estragole, fenchone, $\alpha$-phellandrene and limonene exist as main components. The relative concentration of these compounds varies considerably depending on the origine and phonological state of the fennel (Guillen and Manzanos, 1996; Choi and Hwang, 2004; DiaazMaroto et al., 2006; Gross et al., 2009).

The essential oil is largely used as favoring agent in culinary preparations, confectionary, cordials, liqueurs and occasionally added in scenting soaps (Rupam et al., 2003). Other studies showed that some species extract of this family (Anethum graveolens, Foeniculum vulgare and ferula halophila) have antimicrobial activity against Staphylococcus aureus, Pseudomonas aeruginosa, Vibrio cholera, Escherichia coli, Bacillus subtilis and Candida albicans (Baldemir et al., 2006; Gurinder and Daljit, 2008; Pai et al., 2010).

The current study was meant to assess the antimicrobial properties of the extracts of Foeniculum by using the standard M27-T broth microdilution technique of the National Committee for Clinical Laboratory Standards (NCCLS) (Barchiesi et al., 1994; EspinelIngroff et al., 1995; Bouamama et al., 2006).

We are more interested here on the results of antimicrobial testing of Foeniculum vulgare extracts against Escherichia coli, Enterococcus hirea, Staphylococcus aureus, Pseudomonas aeruginosa and Candida albicans.

\section{MATERIALS AND METHODS}

\subsection{Plant Material}

Leaves of Foeniculum vulgare Mill. were collected in march 2009 from Ouaouizerth, the area of Azilal (Morocco). Specimens were botanically identified at the laboratory of vegetable ecology in the department of Biology, University Cadi Ayyad, Faculty of Sciences Semlalia, of Marrakesh, Morocco.

\subsection{Extracts Preparations}

The extract preparation involves taking dried and finely powdered leaves $(100 \mathrm{~g})$ of the fennel and then extracting it with methanol, using Soxhlet apparatus for 48h. This methanol extract is filtered and then evaporated. The process in question is carried out through an rotary evaporator adjusted under a temperature of $45^{\circ} \mathrm{C}$. Yielding $24 \mathrm{~g}$ (24\%). Both extracts were redissolved in distilled water and successively extracted with hexane, dichloromethane and ethyl acetate. Each organic extract was then evaporated to dryness and labeled as indicated in Table 1.

Afterwards, we prepare approximately $100 \mathrm{mg} \mathrm{mL}^{-1}$ of each extract solution in distilled water. The $\mathrm{pH}$ was adjusted between 5 and 7 . Extracts were sterilized over a membrane filter unit of $0.2 \mu \mathrm{m}$ of pore size and preserved at $+4^{\circ} \mathrm{C}$ until used.

\subsection{Fungal and Bacterial Strains}

Tests were performed on two fungi and four bacteria reference strains obtained from department of biology, Faculty of sciences and technology, Cadi Ayyad University of Marrakesh, Morocco: Candida albicans (ATCC 2091) and Candida albicans (CBS 562), Escherichia coli (CIP 54125), Staphylococcus aureus (CIP 53154), Enterococcus hirea (CIP 5855) and Pseudomonas aeruginosa (CIP A22).

\subsection{Standard Microdilution Method (SMM)}

\subsubsection{Antifungal Activity}

The same M27-T method, which was described by Bouamama et al. (2006), was used again with some modification in terms of culture medium and the concentrations of the extract and of the Amphotericin B. used the same method M27-T described by Bouamama with some modification on the culture medium and the concentrations of the extract and of the Amphotericin B. The culture medium is the Sabouraud dextrose broth (BIOKAR) buffered to $\mathrm{pH} 7$. Amphotericin B was used as standard antibiotic with concentrations ranging from 25 to $0,024 \mu \mathrm{g} \mathrm{mL} \mathrm{m}^{-1}$. The antifungal concentrations ranged from 100 to $0.09 \mathrm{mg} \mathrm{mL}^{-1}$. After inoculation, the plates were incubated for 24,48 and $72 \mathrm{~h}$. at $35^{\circ} \mathrm{C}$.

\subsubsection{Antibacterial Activity}

We used the same method M27-T for the antibacterial test. The culture medium was the Mueller-Hinton broth. Amoxicillin and chloramphenicol (Sigma) were used as standards. Concentrations ranged from 320 to $0.31 \mu \mathrm{g} \mathrm{mL} \mathrm{m}^{-1}$ for amoxicillin and for chloramphenicol. After inoculation, the plates were incubated at $37^{\circ} \mathrm{C}$ for 24 and $48 \mathrm{~h}$. 


\subsubsection{Inoculum Preparation}

Yeast colonies, which obtained from 24h cultures, were taken to another environment called Sabouraud dextrose broth at $35^{\circ} \mathrm{C}$ under agitation. The first suspensions were used for the inocula preparation in the same culture medium. Thomas hematimeter was utilised to determine the concentrations of yeast cells. The concentrations of yeast cells were determined using a Thomas's hematimeter. Budding organisms were counted as two. The original concentrations were adjusted to a concentration of $10^{4}-10^{5}$ colony forming units $(\mathrm{CFU}) / \mathrm{ml}$ with broth used in the susceptibility test.

Stock bacterial inocula suspensions were obtained from $18 \mathrm{~h}$ culture on Mueller-Hinton broth at $37^{\circ} \mathrm{C}$. The suspensions finally yielded serve as the inocula preparation. The cell density of each suspension was determined using a Thomas hematimeter and then adjusted to a concentration of $10^{5}-10^{6} \mathrm{CFU} \mathrm{\textrm {mL } ^ { - 1 }}$ by dilution with Mueller-Hinton broth.

\subsubsection{Readings and Control}

The experiments were repeated three times and the results were determined as an average value. The result readings were made visually. The MIC was considered as the lowest drug concentration of antifungal or antibacterial agent inhibiting the total growth of microorganisms. MIC was detected by lack of visual turbidity (matching the negative growth control). Subcultures were made from the clear wells which did not show any growth after incubation during the MIC assays on nutritive agar with $2 \%$ for bacteria and Potato Dextrose Agar (PDA) (BIOKAR) for fungi.

\section{RESULTS}

The Table 1 shows that the extracts tests had an antimicrobial activity. This activity depends on the nature of the extract, there concentration and bacterial or fungal strain. These results are indeed in line with the previous analysis of the leaves extracts of Foeniculum vulgare Mill., which possessed antimicrobial properties with MIC values ranging from 0.78 to $6.25 \mathrm{mg} \mathrm{mL}^{-1}$ for bacteria and 0.39 to $25 \mathrm{mg} \mathrm{mL}^{-1}$ for fungi.

Extract such as the methanol, hexane, dichloromethane, ethyl acetate and the aqueous extracts of F.vulgare show the lowest MIC and inhibit the development of Escherichia coli, Enterococcus hirea and Staphylococcus aureus. P3 and P4 are the most active extracts (MIC $=0,78 \mathrm{mg} \mathrm{mL}^{-1}$ for $E$. coli and $E$. hirea). $\mathrm{P} 2$ and $\mathrm{P} 5$ are the less active extracts (MIC $=3,125$ for E. coli, E. hirea and P. aeruginosa). $S$. aureus is the most sensitive species to $F$. vulgare with MIC values between $0,78 \mathrm{mg} \mathrm{mL}^{-1}$. Among them, hexane extract show the least active extracts inhibiting $S$. aureus, E. hirea and $P$. aeruginosa with MIC values of $0,78 \mathrm{mg} \mathrm{mL}^{-1}$.

Regarding the fungi studied, we showed that all tested extracts are inhibitory effects on Candida with CMI which vary from 0.39 to $6,25 \mathrm{mg} \mathrm{mL}^{-1} . F$. vulgare extracts have the most compelling inhibition activities against Candida. The species Candida CBS is strongly inhibited by $\mathrm{P} 4$ and P5 (MIC $=0,78 \mathrm{mg} \mathrm{mL}^{-1}$ ) and P1 $\left(\mathrm{MIC}=0,39 \mathrm{mg} \mathrm{mL}^{-1}\right)$. C. albicans CBS and ATCC are the least sensitive strain to the $F$. vulgare extracts $\mathrm{P} 2$ and $\mathrm{P} 3 \quad\left(\mathrm{MIC}=6, \quad 25 \quad \mathrm{mg} \quad \mathrm{mL}^{-1}\right)$.

Table 1. Antibacterial and antifungal activities of $F$. vulgare extracts from Morocco

\begin{tabular}{|c|c|c|c|c|c|c|c|c|}
\hline \multirow[b]{3}{*}{ Microorganisms } & \multirow{2}{*}{\multicolumn{5}{|c|}{$\begin{array}{l}\text { MIC }(\mathrm{mg} / \mathrm{ml}) \\
\text { Extracts }\end{array}$}} & \multicolumn{3}{|c|}{ MIC (mg/ml) } \\
\hline & & & & & & \multicolumn{2}{|c|}{ Antibiotics } & \multirow{2}{*}{$\begin{array}{l}\text { Antifongic } \\
\text { APH B }\end{array}$} \\
\hline & $\mathrm{P} 1$ & $\mathrm{P} 2$ & P3 & P4 & P5 & AMX & CHL & \\
\hline \multicolumn{9}{|l|}{ Gram-positive bacteria } \\
\hline Staphylococcus aureus & 0,78 & 3,125 & 1,56 & 0,78 & 0,78 & 0,00025 & 0,00125 & \\
\hline Enterococcus hirea & 1,56 & 3,125 & 0,78 & 0,78 & 3,125 & 0,00052 & 0,00052 & \\
\hline \multicolumn{9}{|l|}{ Gram-negative bacteria } \\
\hline Escherichia coli & 1,56 & 3,125 & 0,78 & 0,78 & 3,125 & 0,0035 & 0,00125 & \\
\hline $\begin{array}{l}\text { Pseudomonas aeruginosa } \\
\text { Yeast }\end{array}$ & 1,56 & 6,25 & 3,125 & 1,56 & 3,125 & 0,00025 & 0,00125 & \\
\hline Candida albicans ATCC & 3,125 & 6,25 & 6,25 & 25 & 0,78 & & & 0,00156 \\
\hline Candida albicans $C B S$ & 0,39 & 6,25 & 6,25 & 0,78 & 0,78 & & & 0,00156 \\
\hline
\end{tabular}

P1: Methanol extract; P2: Hexane extract; P3: Dichloromethane extract; P4: Ethyl acetate extract; P5: Remaining aqueous layer. AMX: Amoxicilline; CHL: Chloramphenicol; APH B: Amphotericin B 


\section{DISCUSSION}

For many age, medicinal plants have been used to cure diseases. Herbal medicines have increasingly been used to treat effectively infections that are difficult to manage. We are fully aware that plants perfectly produce certain natural chemicals that are toxic to bacteria. A large body of literature has validated the antimicrobial activity of plant extracts (Basile et al., 1999; Pesewu et al., 2008; Babri et al., 2012).

\subsection{Antibacterial Activity}

The results indicated that all extracts have antibacterial activity against examined Gram negative and Gram positive bacteria. Compared with other studies, our data show better antimicrobial activities for Foeniculum species. While observing the therapeutic activity against most of the pathogenic bacteria, gram-positive bacteria were more sensitive to extract than gram-negative bacteria. Gnan and Demello (1999) reported an antimicrobial activity of Goiaba leaves extract at a concentration of $6,5 \mathrm{mg} \mathrm{mL} \mathrm{mL}^{-1}$ against Staphylococcus aureus. Chandrasekaran and Venkatesalu (2004) reported that MIC values of Syzygium jambolanum seed extracts ranged between 0,0031 and $0,5 \mathrm{mg} \mathrm{m} \mathrm{mL}^{-1}$ against $E$. coli, S.aureus, P. aeruginosa and C. albicans. Tanis et al. (2009) reported that chloroform and methanol extract of $N$. arvensis and $N$. unguicularis were the least effective against the microorganisms. These data coincide with those of Okoli and Iroegbu (2004), who reported that water and methanol extracts of some plants displayed a significant antimicrobial activities. Similarly, Basri and Fan (2005) had reported that the aqueous and acetone extracts of galls of Quercus infectoria (Oak) displayed similarities in antimicrobial activity on the bacterial species and as such, it is the potentially source of antimicrobials.

\subsection{Antifungal Activity}

Compared to Amphotericin B, organic extracts of fennel leaves (as shown on the table above) have an effective antifungal activity. these results are perfectly in accordance with those of Zahid et al. (2012) who had reported that the aqueous extract of fennel (Foeniculum vulgare Mill.) had potential antifungal activity against three soil borne: fungi namely: Macrophomina phaseoli, Rhizocotina Solani and Fusarium moniliforme.

\section{CONCLUSION}

To sum up, we basically use the standard M27-T technique to survey the organic and aqueous leaves extracts of Foeniculum vulgare Mill. (Apiaceae) used in traditional medicine, for their antimicrobial properties. Our study has emphasized the fact that the antimicrobial activities are much more significant at Foeniculum species. The leaves extracts of $F$. vulgare species displayed the inhibitory activities against some of the microorganisms involved in many infections and skin diseases.

Although fungi have been the main source of antibiotics up to now, the discovery of new plant products with potential antimicrobial application is of considerable interest in view of the increasing antibiotic resistance to many microorganisms.

This study enables us for further attention of a phytochimical analysis of different extracted and research to identify the active compounds responsible for the biological activity of this plant. More studies $t$ conducted to explicate the exact mechanism of action by which extracts exert their antimicrobial effect.

\section{REFERENCES}

Abed, K.F., 2007. Antimicrobial activity of essential oils of some medicinal plants from Saudi Arabia. Saudi J. Biol. Sci., 14: 53-60.

Babri, R.A., I. Khokhar, Z. Mahmood and S. Mahmud, 2012. Chemical composition and insecticidal activity of the essential oil of Anethum graveolens L. Sci. Int., 24: 453-455.

Baldemir, A.M. Coskunand and S. Yildiz, 2006. Antimicrobial activity of Ferula holophila pesmen. FABAD. J. Pharm. Sci., 31: 57-61.

Barchiesi, F., A.L. Colombo, D.A. McGough and M.G. Rinaldi, 1994. Comparative study of broth macrodilution and microdilution techniques for in vitro antifungal susceptibility testing of yeasts by using the national committee for clinical laboratory standards' proposed standard. Clin. Microbiol., 32: 2494-2500. PMID: 7814488

Barros, L., A.M. Carvalho and I.C.F.R. Ferreira, 2010. The nutritional composition of Fennel (Foeniculum vulgare): Shoots, leaves, stems and inflorescences. LWT-Food Sci. Technol., 43: 814-818. DOI: 10.1016/j.lwt.2010.01.010 
Basile, A., S. Giordano, J.A. Lopez-Saez and R. Cobianchi, 1999. Antibacterial activity of pure flavonoids isolated from mosses. Phytochemistry, 52: 1479-1482. PMID: 10647220

Basri, D.F., S.H. Fan, 2005. The potential of aqueous and acetone extracts of galls of Quercus infectoria as antibacterial agents. Ind. J. Pharmacol., 37: 26-29. DOI: $10.4103 / 0253-7613.13851$

Beaux, D., J. Fleurentin and F. Mortier, 1997. Diuretic action of hydroalcohol extracts of Foeniculum vulgare var dulce (D.C.) roots in rats. Phytotherapy Res., 11: 320-322. DOI: 10.1002/(SICI)10991573(199706)11:4<320::AID-PTR92>3.0.CO;2-N

Bouamama, H., T. Noël, J. Villard, A. Benharref and M. Jana, 2006. Antimicrobial activities of the leaf extracts of two Moroccan cistus L. species. J. Ethnopharmacol., 104: 104-107. PMID: 16213684

Chandrasekaran, M. and V. Venkatesalu, 2004. Antibacterial and antifungal activity of Syzygium jambolanum seeds. J. Ethnopharmacol., 91: 105108. PMID: 15036477

Choi, E.M. and J.K. Hwang, 2004. Antiinflammatory, analgesic and antioxidant activities of the fruit of Foeniculum vulgare. Fitoterapia, 75: 557-565. DOI: 10.1016/j.fitote.2004.05.005

Conforti, F., G. Statti, D. Uzunov and F. Menichini, 2006. Comparative chemical composition and antioxidant activities of wild and cultivated Laurus nobilis L. leaves and Foeniculum vulgare subsp. piperitum (Ucria) coutinho seeds. J. Biol. Pharmaceutical Bull., 29: 2056-2064. PMID: 17015951

Diaaz-Maroto, M.C., M.S. Pea rez-Coello, J. Esteban and J. Sanz, 2006. Comparison of the volatile composition of wild fennel samples (Foeniculum vulgare Mill.) from Central Spain. J. Agric. Food Chem., 54: 6814-6818. DOI: 10.1021/jf0609532

El Bardai, S., B. Lyoussi, M. Wibo and N. Morel, 2001. Pharmacological evidence of hypotensive activity of Marrubium vulgare and Foeniculum vulgare in spontaneously hypertensive rat. Clin. Exp. Hypertens., 23: 329-343. PMID: 11349824

El-Soud, N.A., N. El-Laithy, G. El-Saeed, M.S. Wahby and M. Khalil et al., 2011. Antidiabetic activities of Foeniculum vulgare Mill. Essential oil in Streptozotocin induced diabetic rats. Macedonian J. Med. Sci., 173: 1857-5773. DOI: 10.3889/MJMS.1857-5773.2011.0173
Espinel-Ingroff, A., T.M. Kerkering, P.R. Goldson and S. Shadomy, 1995. Comparison of two alternative microdilution procedures with the national committee for clinical laboratory standards reference macrodilution method $\mathrm{m} 27$-p for in vitro testing of fluconazole-resistant and -susceptible isolates of Candida albicans. J. Clin. Microbiol., 33: 31543158.

Faudale, M., F. Viladomat, J. Bastida, F. Pli and C. Codina, 2008. Antioxidant activity and phenolic composition of wild, edible and medicinal fennel from different Mediterranean countries. J. Agric. Food Chem., 56: 1912-1920. PMID: 18303817

Gnan, S.O. and M.T. Demello, 1999. Inhibition of Staphylococcus aureus by aqueous Goiaba extracts. J. Ethnopharmacol., 68: 103-108. DOI: 10.1016/S0378-8741(99)00048-3

Gross, M., E. Lewinsohn, Y. Tadmor, E. Bar and N. Dudai et al., 2009. The inheritance of volatile phenylpropenes in bitter fennel (Foeniculum vulgare Mill. var. vulgare, Apiaceae) chemotypes and their distribution within the plant. Biochem. Syst. Ecol., 37: 308-316. DOI: 10.1016/j.bse.2009.05.007

Guillen, M.D. and M.J. Manzanons, 1996. A study of several parts of the plant Foeniculum vulgare as a source of compounds with industrial interest. J. Food Res. Int., 29: 85-88. DOI: 10.1016/09639969(95)00047-X

Gurinder, J.K. and S.A. Daljit, 2008. In vitro antibacterial activity of three plants belonging to the family Umbelliferae. Int. J. Antimicrob. Agents, 31: 380-399. DOI: 10.1016/j.ijantimicag.2007.11.007, PMID: 18191549

Heinrich, M., 2005. Understanding local mediterranean diets: A multidisciplinary pharmacological and ethnobotanical approach. J. Pharmacol. Res., 52: 353-366. DOI: 10.1016/j.phrs.2005.06.005

Marino, S.D., F. Gala, N. Borbone, F. Zollo and S. Vitalini et al., 2007. Phenolic Glycosides from Foeniculum Vulgare fruit and evaluation of antioxidative activity. Phytochemistry, 68: 18051812. PMID: 17498761

Okoli, A.S. and C.U. Iroegbu, 2004. Evaluation of extracts of Anthocleista djalonensis, Nauclea latifolia and Uvaria afzalii for activity against bacterial isolates from cases of non-gonococcal urethritis. J. Ethnopharmacol., 92: 135-144. PMID: 15099860 
Oktay, M., I. Gulcin and O.I. Kufrevioglu, 2003. Determination of in vitro antioxidant activity of fennel (Foeniculum vulgare) seed extracts. LWTFood Sci. Technol., 36: 263-271. DOI: 10.1016/S0023-6438(02)00226-8

Ozbek, H., S. Ugras, H. Dulger, I. Bayram and I. Tuncer et al., 2003. Hepatoprotective effect of Foeniculum vulgare essential oil. Fitoterapia, 74: 317-319. DOI: 10.1016/S0367-326X(03)00028-5

Pai, M.B., G.M. Prashant, K.S., Murlikrishna, K.M Shivakumar and G.N. Chandu, 2010. Antifungal efficacy of Punica granatum, Acacia nilotica, Cuminum cyminum and Foeniculum vulgare on Candida albicans: An in vitro study. Ind. J. Dental Res., 21: 334-336. PMID: 20930339

Patra, M., S.K. Shahi, G. Midgely and A. Dikshit, 2002. Utilization of essential oil as natural antifungal against nail-infective fungi. J. Flavour Fragrance, 17: 91-94. DOI: 10.1002/ffj.1049

Pesewu, G.A., R.R. Cutler and D.P. Humber, 2008. Antibacterial activity of plants used in traditional medicines of Ghana with particular reference to MRSA. J. Ethnopharmacol., 116: 102-111. PMID: 18096337

Ruberto, G., M.T. Baratta, S.G. Deans and H.J.D. Dorman, 2000. Antioxidant and antimicrobial activity of Foeniculum vulgare and Crithmum maritimum essential oils. J. Planta Med., 66: 687693. PMID: 11199122
Rupam, K., B. Giri and K.G. Mukerji, 2004. Improved growth and essential oil yield and quality in Foeniculum vulgare Mill on mycorrhizal inoculation supplemented with P-fertilizer. Bioresource Technol., 93: 307-311. DOI: 10.1016/j.biortech.2003.10.028

Surveswaran, S., Y.Z. Cai, H. Corke, M. Sun, 2007. Systematic evaluation of natural phenolic antioxidants from 133 Indian medicinal plants. Food Chem., 102: 938-953. DOI: 10.1016/j.foodchem.2006.06.033

Tanira, M.O.M., A.H. Shah, A. Mohsin, A.M. Ageel and S. Qureshi, 1996. Pharmacological and toxicological investigations on Foeniculum vulgare dried fruit extract in experimental animals. J. Phytotherapy Res., 10: 33-36. DOI: 10.1002/(SICI)10991573(199602)10:1<33::AID-PTR769>3.0.CO;2-L

Tanis, H., A. Aygan and M. Digraka, 2009. Antimicrobial activity of four Nigella species grown in Southern Turkey. Int. J. Agric. Biol., 11: 771-774.

Telci, I., I. Demirtas and A. Sahin, 2009. Variation in plant properties and essential oil composition of sweet fennel (Foeniculum vulgare Mill.) fruits during stages of maturity. Indus. Crops Prod., 30: 126-130. DOI: 10.1016/j.indcrop.2009.02.010

Zahid, N.Y., N.A. Ababsi, I.A. Hafiz, A. Hussain and Z. Ahmad, 2012. Antifungal activity of local fennel (Foeniculum vulgare Mill) extract to growth responses of some soil diseases. Afr. J. Microbiol. Res., 6: 46-51. DOI: 10.5897/AJMR11 